\title{
Recommendations for managing cutaneous disorders associated with advancing age
}

\author{
This article was published in the following Dove Press journal: \\ Clinical Interventions in Aging \\ 12 February 2016 \\ Number of times this article has been viewed
}

\author{
Philippe Humbert ${ }^{1}$ \\ Brigitte Dréno² \\ Jean Krutmann ${ }^{3}$ \\ Thomas Anton Luger ${ }^{4}$ \\ Raoul Triller ${ }^{5}$ \\ Sylvie Meaume 6 \\ Sophie Seité ${ }^{7}$
}

'Research and Studies Centre on the Integument (CERT), Clinical Investigation Centre (CIC BT506),

Department of Dermatology, Besançon University Hospital, University of Franche-Comté, Besançon, France; ${ }^{2}$ Department of Dermato-Cancerology, Nantes University Hospital, Nantes, France; ${ }^{3}$ IUF-Leibniz Research Institute for Environmental Medicine, HeinrichHeine-University, Düsseldorf, Germany; ${ }^{4}$ Department of Dermatology, University of Münster, Münster, Germany; ${ }^{5}$ nternational Centre of Dermatology, Hertford British Hospital, Levallois, France; ${ }^{6}$ Geriatric Service, Wounds and Healing, Rothschild Hôspital, Paris, France; ${ }^{7}$ La Roche-Posay Dermatological Laboratories, Asnières, France
Correspondence: Sophie Seite La Roche-Posay Dermatological Laboratories, II 0 Avenue Henri Barbusse, 92602 Asnières Cedex, France

Tel +33 | 46886544

Fax +33 | 46886688

Email sophie.seite@loreal.com

\begin{abstract}
The increasingly aged population worldwide means more people are living with chronic diseases, reduced autonomy, and taking various medications. Health professionals should take these into consideration when managing dermatological problems in elderly patients. Accordingly, current research is investigating the dermatological problems associated with the loss of cutaneous function with age. As cell renewal slows, the physical and chemical barrier function declines, cutaneous permeability increases, and the skin becomes increasingly vulnerable to external factors. In geriatric dermatology, the consequences of cutaneous aging lead to xerosis, skin folding, moisture-associated skin damage, and impaired wound healing. These problems pose significant challenges for both the elderly and their carers. Most often, nurses manage skin care in the elderly. However, until recently, little attention has been paid to developing appropriate, evidence-based, skincare protocols. The objective of this paper is to highlight common clinical problems with aging skin and provide some appropriate advice on cosmetic protocols for managing them. A review of the literature from 2004 to 2014 using PubMed was performed by a working group of six European dermatologists with clinical and research experience in dermatology. Basic topical therapy can restore and protect skin barrier function, which relieves problems associated with xerosis, prevents aggravating moisture-associated skin damage, and enhances quality of life. In conclusion, the authors provide physicians with practical recommendations to assist them in implementing basic skin care for the elderly in an integrated care approach.
\end{abstract}

Keywords: elderly, skin, cosmetic management

\section{Introduction}

According to the United Nation's World Population Ageing Report, adults over the age of 60 will outnumber younger people by $2050^{1}$ and in Europe alone, more than $20 \%$ of the population will be over 65 years by $2025 .^{2}$ As this population advances in age, many of them will be living with chronic diseases, reduced autonomy, polypathology, and polymedication, which health professionals should consider when managing dermatological problems. As governments encourage the growing trend in Europe to promote aged care in the community, appropriate care from dermatologists, general practitioners, and allied health workers will become increasingly important. ${ }^{3}$

Previously, skin research was focused on improving aesthetic problems and preventing the signs of premature aging. Nowadays, research is turning toward the dermatological problems associated with the loss of cutaneous functions with age. These problems are due to structural and functional changes, driven by an intrinsic, genetically-programmed process, and further aggravated by environmental factors, including lifestyle, sun, and pollution exposure. ${ }^{4}$

As cell renewal slows, the skin becomes increasingly vulnerable to external factors. The physical and chemical barrier function declines, and cutaneous permeability hereby accept the Terms. Non-commercial uses of the work are permitted without any further permission from Dove Medical Press Limited, provided the work is properly attributed. For permission hereby accept the Terms. Non-commercial uses of the work are permitted without any further permission from Dove Mercial use of this work, please see paragraphs 4.2 and 5 of our Terms (https://www.dovepress.com/terms.php).
for 
increases. ${ }^{5}$ Also, thermoregulatory, neurosensory, and immune functions decline. ${ }^{6}$

The consequences of cutaneous aging are particularly relevant in geriatric dermatology. As the skin progressively loses integrity, xerosis occurs, skin folds form, and wound healing is impaired. In the elderly, moisture-associated skin damage (MASD) and wound exacerbation are a significant challenge for both elderly people and their carers. ${ }^{7}$

Most often, nurses manage skin care in the elderly. However, until recently, this role has been considered basic, and so little attention was paid to developing appropriate, evidence-based, skincare protocols. Unsurprisingly, hygiene practices vary widely among care providers and within institutions, ${ }^{8}$ and are performed according to habit rather than science. ${ }^{9}$ Furthermore, skincare activities are often delegated to less experienced staff who are insufficiently trained..$^{10}$ However, as the cost of nursing care required to manage these problems is rising, skin breakdown incidents are being used as reporting measures of nursing quality in the UK. Cosmetic use in dermatology has been established over time to protect, restore, or maintain skin barrier function and microbial diversity. This involves appropriately using gentle cleansers, humectants, emollients, photoprotective creams, makeup, and specific wound care.

As elderly people have different skincare needs, and in the absence of evidence-based literature to describe the best skincare protocol, both health care providers and carers need appropriate advice and training. The objective of this paper is to highlight common clinical problems with aging skin and provide some appropriate advice on skincare protocols for managing them.

\section{Methodology}

This paper follows a meeting in September 2014 of a board of six European dermatologists, specialized in dermatology, cosmetology, and geriatrics. During the meeting, the board defined and discussed the key topics, in view of the literature and their clinical experience. Each author conducted a literature search in their area of expertise using PubMed, and papers were selected between 2004 and 2014. Where no recent data were available, earlier papers were explored and their conclusions discussed. The initial key words included skin barrier, emollient, skin ageing, geriatrics, well-being, incontinence associated dermatitis, MASD, skin cleansers, cosmetology, cosmetic ingredients, biophysics, and skin disease elderly, etc. Where no original research was available, references were made from review articles.

\section{Common cutaneous disorders}

Age-related skin changes often result in dermatological disorders and skin injury. ${ }^{11}$ One of the most common issues for mature adults is xerosis, which is caused by diminished natural moisturizing factors, sebum, and lipid production. ${ }^{12}$ Skin aging is often associated with pruritus.

Skin tears are a common consequence of extreme agerelated frailty that some authors have begun to refer to as dermatoporosis. Most lesions occur on the forearms, caused by removing adhesive dressings or bumping into furniture. However, tears can occur from friction caused by other nursing activities such as changing stoma application or devices. There are no current treatments for dermatoporosis.

MASD describes an ensemble of skin problems that arise from barrier dysfunction caused by prolonged exposure to moisture in an occluded environment. ${ }^{13}$ Also, moisture contact increases the skin's friction coefficient, increasing the risk of skin erosion and pressure ulcers. MASD is most often related to urinary-associated incontinence (incontinenceassociated dermatitis [IAD]), intertrigo, ostomy leakage, and peri-wound skin, each with a specific etiology. ${ }^{14}$

$\mathrm{IAD}$, also referred to as perineal dermatitis, has been reported to affect up to $50 \%$ of nursing home residents and between $10 \%$ and $35 \%$ of community-dwelling elders. ${ }^{7}$ Other smaller scale studies have reported that $30 \%-50 \%$ of people wearing absorbent pads suffer from perineal dermatitis. ${ }^{15}$ The etiology of IAD is a complex combination of skin contact with moisture and chemical irritants, such as urea, fecal proteases, lipases, and bile salts, in an occluded environment. ${ }^{16}$ Additionally, when cutaneous flora breaks down urea, skin surface $\mathrm{pH}$ increases, further favoring microorganism growth and dysbiosis. ${ }^{17}$ Normally, commensal organisms are allowed to colonize, causing infection and inflammation. In turn, skin permeability increases, and barrier function decreases. Making matters worse, this chemical irritation is further aggravated by friction and stratum corneum (SC) lipid loss from frequently washing the affected area. ${ }^{18}$ Additional pressure from a bed or chair contributes to skin breakdown and cutaneous erosion. Once this vicious cycle commences, it not only incurs high nursing costs but also severely reduces clinical outcomes and quality of life. ${ }^{19,20}$ A Dutch study estimated the cost of treating pressure ulcers could range between $€ 206.3$ million and $€ 238.1$ million. $^{21}$

Peri-stomatic dermatitis is an MASD that occurs in elderly people with existing stomas where, over time, their skin begins to wrinkle and fold around their application or device. Skin wrinkling may also be an issue for elderly patients when a new stoma is placed. These wrinkles, skin folds, or creases 
in the peri-stomal skin prevent the stoma adhering properly, and fluid leaks between the stoma appliance and abdominal skin, causing skin breakdown. ${ }^{22,23}$

Intertrigo is an MASD caused by perspiration trapped in body folds resulting from skin sagging with age, increasing the number of skin folds in the inguinal region, armpits, and underside of the breasts or belly. Trapped moisture causes barrier dysfunction, inflammation, erythema, maceration, and skin weeping. Microfloral imbalance may also allow secondary infections such as Candida albicans to grow.

Peri-wound exudate also causes MASD in unprotected peri-wound areas. Moisture damage causes erythema, erosion, maceration, and skin weeping.

Unfortunately, MASD in general has been largely overlooked and, so, inappropriately managed. ${ }^{24}$ The traditional soap and water wash followed by towel drying is damaging and may have a cumulative effect in disrupting skin barrier function. ${ }^{25-27}$

Yet, the benefits of well-defined skincare protocols in managing skin disorders and preventing skin injury have been highlighted by several studies based both in Europe and North America. Bale et al reported that by introducing an educational program with a skincare protocol for elderly patients with incontinence, skin breakdown and dermatitis were prevented in their study population. ${ }^{28}$ More recently, the National Health Service (NHS), Institute for Innovation and improvement (UK, 2010) launched the "Your Skin Matters" scheme, which emphasizes skin care for incontinence management. ${ }^{29}$ Although further research is required to define an optimal skincare regimen, the current trend is one that enables frequent cleansing without compromising skin barrier function. ${ }^{30}$

Actinic keratosis (AK) is a common skin condition caused by the cumulative effects of long-term sun exposure that can potentially progress to nonmelanoma skin cancer. The prevalence rises to over $80 \%$ in people aged 60 to 69 years $^{31}$ and the risk for developing $\mathrm{AKs}$ increases with being male (odds ratio $[\mathrm{OR}]=3.9)$, having fair $\operatorname{skin}(\mathrm{OR}=2.2)$, a history of skin cancer $(\mathrm{OR}=4.8)$, irregular sunscreen use $(\mathrm{OR}=1.81)$, and occupational solar exposure $(\mathrm{OR}=1.7) .{ }^{32}$ Certain immunocompromised populations such as organ transplant recipients are also particularly susceptible to AKs. ${ }^{33,34}$

\section{Histological changes of skin barrier function loss \\ Barrier dysfunction}

The SC and its inhabiting microbiota together provide the skin barrier function. Its effectiveness relies upon SC thickness, intracellular lipid content, and lipid organization. The effect of intrinsic aging on skin barrier function remains controversial due to the scarcity of research in this area to date and the difficulty in distinguishing between intrinsic and extrinsic influences. ${ }^{35}$ However, we know that as the keratinocyte turnover slows, the keratinization and desquamation processes alter. ${ }^{36}$ Keratinocyte transformation to corneocytes to form the cornified envelope is calcium-dependent and starts in the stratum granulosum. A recent study found the composition of the cornified envelope changes with age, as calcium is redistributed away from the stratum granulosum.

Also, the lipid-protein membranes and intercellular junctions between corneocytes are destroyed. Recent biophysical research has shown that although transepidermal water loss (TEWL) levels appear to remain consistent with age, skin hydration reduces. The supply of SC lipids, such as ceramide, cholesterol, free fatty acids decrease and a reduced sebaceous and sweat production further limits skin lipid supply. ${ }^{35}$

Additionally, slowing cellular renewal with advancing age delays the epidermal barrier reconstruction following alterations due to irritation. This is due to decreased enzyme activity involved in lipid synthesis, a modified cytokine profile, and alterations in epidermal stem cell function. ${ }^{37}$

\section{Protective mechanical function loss}

Protective mechanical function is the ability of the skin to resist bumps and friction, which is reduced with cutaneous atrophy and elasticity loss. Dermatoporosis is an emerging term, recently coined by Kaya and Saurat ${ }^{42}$ to describe this extreme cutaneous fragility caused by progressive, protective mechanical function loss with advancing age. The term draws its name from the resemblance to bone fragility caused by osteoporosis. It seems to be due to a loss of one main constituent of skin tissue, hyaluronic acid. However, a constant rise in spring-like small proline-rich repeat (SPRR) proteins and a decrease in flexible and insoluble loricrin (LOR) proteins have been found in aged skin, which may also contribute to this mechanical function loss. ${ }^{38-40}$ Therefore, the skin becomes increasingly vulnerable to bumps and friction. The prevalence is uncertain, as few epidemiological studies have investigated this problem, although one French study estimated that $32 \%$ of elderly people (over 60 years) are affected. ${ }^{41}$ Severity ranges from: 1) extreme skin thinning, purpura, and pseudoscars; 2) skin lacerations resulting from minor traumas; 3 ) larger and more numerous skin lacerations and delayed wound healing; and 4) advanced lesions with subcutaneous bleeding, leading to dissecting hematomas and, potentially, skin necrosis. ${ }^{42}$ 


\section{Neurosenescence}

Tactile acuity declines as the density of free or encapsulated nerve endings decreases (ie, Meissner's, Pacini's, or Ruffini's corpuscles). ${ }^{43}$ Pain and touch thresholds also increase, possibly due to subclinical neuropathy. ${ }^{44}$ Senile pruritus has also been attributed to this subclinical neuropathy, although the pathogenesis remains poorly understood. ${ }^{45,46}$

\section{Immunosenescence}

Immunosenescence or "inflammaging" is a new concept in aging research, and is gaining increasing attention. It is characterized as a low-grade inflammation that provides a background environment that allows infections and slows wound healing. ${ }^{47}$ With age, the innate immune system becomes increasingly dominant. We currently understand that the mechanisms behind these changes include modified innate immune cell receptor activity and their downstream signaling pathways as well as changes to the numbers of various cells within the circulation, particularly decreased T-cell number and diversity. ${ }^{48}$

There is reduced neutrophil adhesion to vascular endothelium, migration and chemotactic activity, uptake and killing of microbes, and response to cytokines and Toll-like receptor (TLR) release.

An effective innate immune system is critical for skin barrier function, stimulating appropriate adaptive immune responses and determining the character of the skin microbiote. ${ }^{49,50}$ A weakened immune system can alter the skin barrier function by changing the host microbial composition, allowing other microorganisms to penetrate through the skin and participate in the state of chronic inflammation. ${ }^{47}$ The result of this is, for example, more frequent viral (herpes zoster), bacterial, and fungal infections seen in the elderly.

\section{Key modulating factors of skin aging}

The genetically-programmed, physiological aging process is accelerated by extrinsic biological factors. Many such factors have been identified, but the sun is well known to be the most aggressive. Some authors estimated that sun exposure was responsible for $80 \%$ of visible facial aging signs. ${ }^{51}$ Smoking also accelerates skin aging by inducing premature elastosis, ${ }^{52}$ increasing matrix metalloproteinases production, and breaking down collagen. ${ }^{53,54}$ Alarmingly, a recent German study, showed air particle pollution is also an accelerator. ${ }^{55,56}$ Other lifestyle influences such as social status and depression have been shown in twin studies to affect facial aging. ${ }^{57}$

\section{Cosmetics in the management of skin problems with aging}

Cosmetics in the elderly are used to maintain skin integrity, improve quality of life, and help maintain a positive self-esteem. Kligman was one of the earliest dermatologists to report that wearing makeup improved self-esteem in elderly women, which has been recently reiterated following work with oncology patients. ${ }^{58,59}$ Makeup can be used to enhance the shape of lips, cheeks, or eyelids that have changed with age. ${ }^{60}$

\section{Skin cleansing}

Certain conditions in the elderly, such as IAD, require the skin to be cleaned more often. Implementing skincare protocols that recommend using a body wash such as syndet with a neutral $\mathrm{pH}$ and a skin protectant reduces the incidence of Stage I and Stage II pressure ulcers and decreases healing time. ${ }^{61}$

The literature comparing cleansers to soap and water includes some small studies and mostly clinical observation and expert panel sources. Nevertheless, compared with managing IAD wounds, cleansers have been reported to have therapeutic, practical, and economic advantages, especially when combined with an emollient. ${ }^{15,27,62,63}$

\section{Skin hydration}

Emollient therapy for the body to manage xerosis requires both humectants and lipid content replacement. ${ }^{64,65}$ This restores and protects cutaneous barrier function. Emollients can be composed of hydrogenated or nonhydrogenated vegetable oils, mineral oils (eg, paraffin or petroleum jelly), vegetable butters (eg, shea or cocoa), alcohols, fatty acids, and esters, triglycerides, and ceramides. Emollients with a rich concentration of skin lipids such as ceramides in a concentration of $20 \%-40 \%$ are preferable. Hygroscopic agents ( $\alpha$ - and $\beta$-hydroxy acids, lactic acid, urea, glycerol) attract water to the stratum corneum. ${ }^{66}$ Normally hydrated skin, with an intact barrier, will resist irritation from body fluids and is less likely to crack or tear. Emollients also relieve pruritus associated with xerosis and can help establish the microfloral balance.

To treat xerosis, consistent and regular moisturizer use is as important as the formulation of the moisturizer alone. ${ }^{67}$

When treating skin xerosis in the elderly, the dry skin scaling should nearly disappear after 28 days of topical administration of the cream. Occlusive creams, that is, those containing glycerol and paraffin, seem to be more able to control the xerosis in this population. By improving skin hydration, there is a significative reduction in itching and TEWL. ${ }^{68}$ 


\section{Irritant protection}

When the natural barrier function is weakened, barrier products are used to protect the skin from contact with chemical irritants such as feces, urine, or excessive exposure to water. These preparations are usually made with a lipid/water emulsion base and a metal oxide, for example, zinc or titanium, ${ }^{69}$ or silicone-based ingredient such as dimethicone. Some recent products form a protective layer on the skin surface as a semipermeable polymer coating. ${ }^{10}$

Appropriate ingredients that promote healing include sucralfate or madecassoside. ${ }^{70}$ To relieve irritation, panthenol ${ }^{71}$ or even mild antibacterial agents such as copper or zinc salts are effective. ${ }^{72}$

Using a thin layer of barrier cream around a stoma opening has been suggested to protect and moisturize the skin without making it greasy. Barrier creams containing glycerol and silicone gel do not interfere with the pouch adhesion if used sparingly. ${ }^{73}$

\section{Daily photoprotection}

Although aged skin is less sensitive to UV radiation, daily photoprotection with UVA and UVB sunscreen in people aged 40 years or older is recommended to help prevent AK and squamous cell carcinomas from developing. ${ }^{34,74}$

In addition to lifestyle factors, physiological changes reduce the dermal capacity to produce vitamin D. ${ }^{75}$ One recent, large, epidemiological report confirmed vitamin $\mathrm{D}$ deficiency to be alarmingly high ( $>50 \%)$ during winter and spring months in the community-dwelling, elderly population in the UK. However, providing vitamin D supplements has been shown to increase circulating 25(OH)D concentrations. Thus, to improve circulating vitamin $\mathrm{D}$ levels, it would be preferable to provide vitamin D supplements and maintain photoprotection when outdoors to prevent further skin damage. ${ }^{76}$

\section{Encourage well-being}

Although physical appearance is not usually a primary concern in elderly patients, makeup, hair coloration, styling, wigs, and perfume can make them feel more positive. The human contact with beauticians can be beneficial. $59,60,77$

\section{Education}

Nurses are well placed to provide appropriate cleansing, protection, and skin hydration. However, the expert panel reiterated the need to correctly recognize the condition at hand, using validated tools or instruments, particularly among dermatitis, MASD, and pressure ulcers, which are difficult to differentiate. ${ }^{78,79}$ Although basic skincare protocols are being implemented in some countries, further research is required into the most appropriate protocol for managing IAD. Considering correct skin cleansing techniques have been shown to reduce MASD, the authors suggest that health care professionals, patients, and professionals are properly educated and prepared to manage IAD and chronic wounds.

\section{Formulation and packaging}

Caring for the elderly is often associated with high costs, reduced economic resources, and physical incapability. Slightly damaged skin may become irritated by certain ingredients, perfumes, or preservatives. Formulation chemistry ensures a careful balance between ingredients to obtain adequate efficacy, cosmetic quality, and tolerability. Packaging chosen by cosmetic manufacturers may impact the affordability and prevent the products being applied adequately. Certain products combining cleansers with emollients, such as wipes or foams, have been shown to be as effective as soap and water ${ }^{80}$ and useful in practice, if tolerance is adequate. ${ }^{81}$

In the absence of any literature describing appropriate packaging, the board made several suggestions drawn from clinical experience and a recent market research study (Taylor Nelson Sofres, unpublished data, August, 2010). They suggest when designing packaging that the reduced physical dexterity of the elderly be considered. Packs should be easy to open, read, and handle. Additionally, packaging that is easy for elderly people to open and use may help to make reality of age-related physical decline more livable.

\section{Discussion and expert recommendations}

The evidence suggests that certain cutaneous disorders in the elderly can be managed by improving cutaneous barrier function. The expert group believes that skin care also remains an essential part of well-being and, to this end, suggest appropriate skin care, based upon the available evidence on the role of cosmetics in maintaining skin integrity (Table 1).

1. A gentle cleanser, ideally with an emollient, is appropriate for washing older skin. Avoid soap and water and take extreme care when washing or drying to avoid additional friction.

2. Emollient therapy containing humectants and skin lipid replacement agents is useful for managing xerosis and pruritus. Emollients also improve fragile skin (dermatoporosis). They soften brittle skin and may prevent tearing, particularly if they contain an ingredient that stimulates hyaluronic acid synthesis. Emollients containing a promicrobial ingredient 
Table I Practical recommendations for the management of cutaneous disorders in the elderly

\begin{tabular}{lll}
\hline Skin problem & Objective & Practical recommendation \\
\hline Daily skin care for fragile skin & - Protect skin barrier (hydrate, replenish) & $\begin{array}{l}\text { Gentle cleansers: } \\
\text { - Ideally with an emollient }\end{array}$ \\
- Maintain healthy cutaneous microflora & - Avoid soap and water \\
Xerosis & & - Avoid friction when washing or drying \\
Pruritus & - Repair skin barrier & Emollient therapy containing: \\
Skin tears & - Promote healing & - Humectants and skin lipid replacement agents \\
& - Restore microflora & - Ingredients that stimulate hyaluronic acid synthesis \\
& & soften brittle skin and may prevent tearing \\
Wound healing & - Promote epithelialization & - Promicrobial ingredients can improve the \\
Preventing moisture-associated & immunological barrier and wound healing \\
skin disease & - Protect skin barrier from chemical & - A healing balm \\
& irritants & Implement an optimal skincare regimen: \\
Actinic keratosis & Prevent friction & - A gentle skin cleanser and emollient \\
Patient and carer education & - Ensure skincare protocols are correctly & - Barrier creams containing glycerol or silicone gel \\
& implemented & Protect the skin barrier
\end{tabular}

Abbreviation: UV, ultra violet.

can improve the immunological barrier and wound healing. If epidermal injury occurs, a healing balm could be applied to improve the re-epithelialization.

3. MASD-related problems can be prevented by implementing an optimal skincare regimen that enables frequent washing without compromising skin barrier function.

4. AKs can be prevented by continuing to apply a broadspectrum sunscreen to exposed skin from 40 years of age. $^{82}$

5. Allied health professionals and carers should be adequately educated and supported in adopting appropriate skincare protocols. Dermatologists are well placed to advise allied health professionals and carers on appropriate skincare protocols.

\section{Conclusion}

These suggestions are intended to support basic skin care in the elderly, either in the community or within aged care facilities. In this setting, the key role is to maintain skin barrier function to prevent some dermatological problems and improve the quality of life. The authors recognize that further research is required to define an optimal skincare regimen.

\section{Acknowledgments}

This paper was funded with a grant from La Roche-Posay, France. Amy Whereat from Speak the Speech Consulting provided medical writing assistance for this article.

\section{Disclosure}

The authors report no conflicts of interest in this work.

\section{References}

1. United Nations. World Population Ageing: 1950-2050. New York: United Nations; 2001.

2. European Commission. Ageing. Available from: http://ec.europa.eu/ health/ageing/policy/index_en.htm. Accessed: December 2014.

3. Rechel B, Doyle Y, Grundy E, McKee M. Policy Brief 10: How can health systems respond to population ageing? Geneva: World Health Organization; 2009:36.

4. Warren R, Gartstein VP, Kligman AM, Montagna W, Allendorf RA, Ridder GM. Age, sunlight, and facial skin: a histologic and quantitative study. J Am Acad Dermatol. 1991;25:751-760.

5. Konda S, Meier-Davis SR, Cayme B, Shudo J, Maibach HI. Agerelated percutaneous penetration part 1: skin factors. Skin Therapy Lett. 2012;17:5-7.

6. Thornton MJ. Estrogens and aging skin. Dermatoendocrinology. 2013;5:264-270.

7. Newman D. Moisture control, urinary and faecal incontinence, and perineal skin management. In: Krasner D, Rodeheaver GT, Sibbald Rg, Woo KY, editors. Chronic Wound Care: A Clinical Source Book for Healthcare Professionals. Malvern, PA: HMP Communications; 2007:609-627.

8. Kottner J, Rahn Y, Blume-Peytavi U, Lahmann N. Skin care practice in German nursing homes: a German-wide cross-sectional study. J Dtsch Dermatol Ges. 2013;11:329-336.

9. Jeter KF, Lutz JB. Skin care in the frail, elderly, dependent, incontinent patient. Adv Wound Care. 1996;9:29-34.

10. Voegeli D. Care or harm: exploring essential components in skin care regimens. Br J Nurs. 2010;19:810, 812, 814, passim.

11. Roberts W. Dermatologic problems of older women. Dermatol Clin. 2006;24:271-280.

12. White-Chu EF, Reddy M. Dry skin in the elderly: complexities of a common problem. Clin Dermatol. 2011;29:37-42.

13. Fluhr JW, Lazzerini S, Distante F, Gloor M, Berardesca E. Effects of prolonged occlusion on stratum corneum barrier function and water holding capacity. Skin Pharmacol Appl Skin Physiol. 1999;12:193-198. 
14. Voegeli D. Moisture-associated skin damage: aetiology, prevention and treatment. Br J Nurs. 2012;21:517-518, 520-521.

15. Ersser SJ, Getliffe K, Voegeli D, Regan S. A critical review of the inter-relationship between skin vulnerability and urinary incontinence and related nursing intervention. Int J Nurs Stud. 2005;42:823-835.

16. Buckingham KW, Berg RW. Etiologic factors in diaper dermatitis: the role of feces. Pediatr Dermatol. 1986;3:107-112.

17. Faergemann J, Aly R, Wilson DR, Maibach HI. Skin occlusion: effect on Pityrosporum orbiculare, skin $\mathrm{PCO} 2, \mathrm{pH}$, transepidermal water loss, and water content. Arch Dermatol Res. 1983;275:383-387.

18. Fader M, Clarke-O'Neill S, Cook D, et al. Management of night-time urinary incontinence in residential settings for older people: an investigation into the effects of different pad changing regimes on skin health. J Clin Nurs. 2003;12:374-386.

19. Bennett G, Dealey C, Posnett J. The cost of pressure ulcers in the UK Age Ageing. 2004;33:230-235.

20. Kottner J, Lichterfeld A, Blume-Peytavi U. Maintaining skin integrity in the aged: a systematic review. Br J Dermatol. 2013;169: $528-542$.

21. Schuurman JP, Schoonhoven L, Defloor T, van Ramshorst B, Buskens E. Economic evaluation of pressure ulcer care: a cost minimization analysis of preventive strategies. Nurs Econ. 2009;27: 390-400, 415 .

22. Turnbull GB. Minding the gap: the art of managing peristomal topography. Ostomy Wound Manage. 2006;52:11-12.

23. Borwell B, Breckman B. Practical management of bowel stomas. In: Breckman B, editor. Stoma Care and Rehabilitation. Oxford: Churchill Livingstone; 2006:41-68.

24. Geraghty J. Introducing a new skin-care regimen for the incontinent patient. Br J Nurs. 2011;20:409-410, 412, 414-415.

25. Doughty D, Junkin J, Kurz P, et al. Incontinence-associated dermatitis: consensus statements, evidence-based guidelines for prevention and treatment, and current challenges. $J$ Wound Ostomy Continence Nurs. 2012;39:303-315. Quiz 316-317.

26. Voegeli D. The effect of washing and drying practices on skin barrier function. $J$ Wound Ostomy Continence Nurs. 2008;35:84-90.

27. Bliss DZ, Zehrer C, Savik K, Smith G, Hedblom E. An economic evaluation of four skin damage prevention regimens in nursing home residents with incontinence. J Wound Ostomy Continence Nurs. 2007;34 143-152.

28. Bale S, Tebble N, Jones V, Price P. The benefits of implementing a new skin care protocol in nursing homes. J Tissue Viability. 2004;14: 44-50.

29. Institute NHS. Your Skin Matters; 2010. Available from: http://www institute.nhs.uk/building_capability/hia_supporting_info/your_skin_ matters.html. Accessed January 2015.

30. Voegeli AC. Care or harm: exploring essential components in skin care regimens. Br J Nurs. 2010;19:810, 812, 814.

31. Schwartz RA, Bridges TM, Butani AK, Ehrlich A. Actinic keratosis: an occupational and environmental disorder. $J$ Eur Acad Dermatol Venereol. 2008;22:606-615.

32. Hensen P, Muller ML, Haschemi R, et al. Predisposing factors of actinic keratosis in a North-West German population. Eur J Dermatol. 2009, 19:345-354.

33. Savoia P, Stroppiana E, Cavaliere G, et al. Skin cancers and other cutaneous diseases in renal transplant recipients: a single Italian center observational study. Eur J Dermatol. 2011;21:242-247.

34. Chetty P, Choi F, Mitchell T. Primary care review of actinic keratosis and its therapeutic options: a global perspective. Dermatol Ther (Heidelb). 2015;5:19-35.

35. Luebberding S, Krueger N, Kerscher M. Age-related changes in skin barrier function - quantitative evaluation of 150 female subjects. Int $J$ Cosmet Sci. 2013;35:183-190.

36. Tsugita T, Nishijima T, Kitahara T, Takema Y. Positional differences and aging changes in Japanese woman epidermal thickness and corneous thickness determined by OCT (optical coherence tomography). Skin Res Technol. 2013;19:242-250.
37. Seyfarth F, Schliemann S, Antonov D, Elsner P. Dry skin, barrier function, and irritant contact dermatitis in the elderly. Clin Dermatol. 2011; 29:31-36.

38. Jackson B, Tilli CM, Hardman MJ, et al. Late cornified envelope family in differentiating epithelia - response to calcium and ultraviolet irradiation. J Invest Dermatol. 2005;124:1062-1070.

39. Rinnerthaler M, Duschl J, Steinbacher P, et al. Age-related changes in the composition of the cornified envelope in human skin. Exp Dermatol. 2013;22:329-335.

40. Steinert K, Wagner V, Kroth-Pancic PG, Bickel-Sandkotter S. Characterization and subunit structure of the ATP synthase of the halophilic archaeon Haloferax volcanii and organization of the ATP synthase genes. J Biol Chem. 1997;272:6261-6269.

41. Mengeaud V, Dautezac-Vieu C, Josse G, Vellas B, Schmitt AM. Prevalence of dermatoporosis in elderly French hospital in-patients: a cross-sectional study. Br J Dermatol. 2012;166:442-443.

42. Kaya G, Saurat JH. Dermatoporosis: a chronic cutaneous insufficiency/ fragility syndrome. Clinicopathological features, mechanisms, prevention and potential treatments. Dermatology. 2007;215:284-294.

43. Stevens JC, Choo KK. Spatial acuity of the body surface over the life span. Somatosens Mot Res. 1996;13:153-166.

44. Nusbaum NJ. Aging and sensory senescence. South Med J. 1999;92: 267-275.

45. Gatti S, Serri F. Phantom itch, pseudophantom itch, and senile pruritus. Int J Dermatol. 1994;33:522.

46. Ward JR, Bernhard JD. Willan's itch and other causes of pruritus in the elderly. Int J Dermatol. 2005;44:267-273.

47. Vasto $\mathrm{S}$, Candore $\mathrm{G}$, Balistreri $\mathrm{CR}$, et al. Inflammatory networks in ageing, age-related diseases and longevity. Mech Ageing Dev. 2007;128: 83-91.

48. Panda A, Arjona A, Sapey E, et al. Human innate immunosenescence: causes and consequences for immunity in old age. Trends Immunol. 2009;30:325-333.

49. Kong HH, Segre JA. Skin microbiome: looking back to move forward. J Invest Dermatol. 2012;132:933-939.

50. Kuo IH, Yoshida T, De Benedetto A, Beck LA. The cutaneous innate immune response in patients with atopic dermatitis. J Allergy Clin Immunol. 2013;131:266-278.

51. Flament F, Bazin R, Laquieze S, et al. Effect of the sun on visible clinical signs of aging in Caucasian skin. Clin Cosmet Investig Dermatol. 2013;6:221-232.

52. Yang GY, Zhang CL, Liu XC, et al. Effects of cigarette smoke extracts on the growth and senescence of skin fibroblasts in vitro. Int J Biol Sci. 2013;9:613-623.

53. Just M, Ribera M, Monso E, et al. Effect of smoking on skin elastic fibres: morphometric and immunohistochemical analysis. Br J Dermatol. 2007;156:85-91.

54. Yin L, Morita A, Tsuji T. Alterations of extracellular matrix induced by tobacco smoke extract. Arch Dermatol Res. 2000;292: 188-194.

55. Valacchi G, Sticozzi C, Pecorelli A, Cervellati F, Cervellati C, Maioli E. Cutaneous responses to environmental stressors. Ann N Y Acad Sci. 2012; 1271:75-81.

56. Vierkotter A, Schikowski T, Ranft U, et al. Airborne particle exposure and extrinsic skin aging. J Invest Dermatol. 2010;130: 2719-2726.

57. Rexbye H, Petersen I, Johansens M, Klitkou L, Jeune B, Christensen K. Influence of environmental factors on facial ageing. Age Ageing. 2006; $35: 110-115$.

58. Taggart L, Ozolins L, Hardie H, Nyhof-Young J. Look good feel better workshops: a "big lift" for women with cancer. J Cancer Educ. 2009;24:94-99.

59. Kligman AM. Psychological aspects of skin disorders in the elderly. Cutis. 1989;43:498-501.

60. Ramos-e-Silva M, da Silva Carneiro SC. Elderly skin and its rejuvenation: products and procedures for the aging skin. $J$ Cosmet Dermatol. 2007;6:40-50 
61. Thompson P, Langemo D, Anderson J, et al. Skin care protocols for pressure ulcers and incontinence in long-term care: a quasi-experimental study. Adv Skin Wound Care 2005;18:422-429.

62. Cooper P, Gray D. Comparison of two skin care regimes for incontinence. Br J Nurs. 2001;10:S6, S8, S10, passim.

63. Beeckman D, Schoonhoven L, Verhaeghe S, Heyneman A, Defloor T. Prevention and treatment of incontinence-associated dermatitis: literature review. J Adv Nurs. 2009;65:1141-1154.

64. Hurlow J, Bliss DZ. Dry skin in older adults. Geriatr Nurs. 2011;32: 257-262.

65. Pons-Guiraud A. Dry skin in dermatology: a complex physiopathology. J Eur Acad Dermatol Venereol. 2007;21 suppl 2:1-4.

66. Seite S, Bieber T. Barrier function and microbiotic dysbiosis in atopic dermatitis. Clin Cosmet Investig Dermatol. 2015;8:479-483.

67. Shim JH, Park JH, Lee JH, Lee DY, Lee JH, Yang JM. Moisturizers are effective in the treatment of xerosis irrespectively from their particular formulation: results from a prospective, randomized, doubleblind controlled trial. J Eur Acad Dermatol Venereol. Epub 2015 Nov 13.

68. Cristaudo A, Francesconi L, Ambrifi M, Frasca M. Cavallotti C, Sperduti E. Efficacy of an emollient dermoprotective cream in the treatment of elderly skin affected by xerosis. G Ital Dermatol Venereol. 2015;150:297-302.

69. Arad A, Mimouni D, Ben-Amitai D, Zeharia A, Mimouni M. Efficacy of topical application of eosin compared with zinc oxide paste and corticosteroid cream for diaper dermatitis. Dermatology. 1999;199:319-322.

70. Liu M, Dai Y, Li Y, et al. Madecassoside isolated from Centella asiatica herbs facilitates burn wound healing in mice. Planta Med. 2008;74:809-815.

71. Ebner F, Heller A, Rippke F, Tausch I. Topical use of dexpanthenol in skin disorders. Am J Clin Dermatol. 2002;3:427-433.

72. Tenaud I, Sainte-Marie I, Jumbou O, Litoux P, Dreno B. In vitro modulation of keratinocyte wound healing integrins by zinc, copper and manganese. Br J Dermatol. 1999;140:26-34.
73. Wounds UK. Best Practice Statement: The use of topical antiseptic/ antimicrobial agents in wound management. London: Wounds UK; 2011. Available from: http://www.wounds-uk.com/best-practicestatements/. Accessed January 2015.

74. de Berker D, McGregor JM, Hughes BR. Guidelines for the management of actinic keratoses. Br J Dermatol. 2007;156:222-230.

75. MacLaughlin J, Holick MF. Aging decreases the capacity of human skin to produce vitamin D3. J Clin Invest. 1985;76:1536-1538.

76. Hill TR, Granic A, Davies K, et al. Serum 25-hydroxyvitamin D concentration and its determinants in the very old: the Newcastle 85+ study. Osteoporos Int. Epub 2015 Oct 14.

77. Giuli C, Papa R, Marcellini F, et al. The role of psychological wellbeing in obese and overweight older adults. Int Psychogeriatr. 2016; 28:171-172.

78. Borchert K, Bliss DZ, Savik K, et al. The incontinence-associated dermatitis and its severity instrument: development and validation. $J$ Wound Ostomy Continence Nurs. 2010;37:527-535.

79. Beeckman D, Schoonhoven L, Fletcher J, et al. Pressure ulcers and incontinence-associated dermatitis: effectiveness of the pressure ulcer classification education tool on classification by nurses. Qual Saf Health Care. 2010;19:e3.

80. Ronner AC, Berland CR, Runeman B, Kaijser B. The hygienic effectiveness of 2 different skin cleansing procedures. $J$ Wound Ostomy Continence Nurs. 2010;37:260-264.

81. Baadjies R, Karrouze I, Rajpaul K. Using no-rinse skin wipes to treat incontinence-associated dermatitis. Br J Nurs. 2014;23 Suppl 20: S22-S28.

82. Olsen EA, Abernethy ML, Kulp-Shorten C, et al. A double-blind, vehicle-controlled study evaluating masoprocol cream in the treatment of actinic keratoses on the head and neck. J Am Acad Dermatol. 1991;24:738-743.
Clinical Interventions in Aging

\section{Publish your work in this journal}

Clinical Interventions in Aging is an international, peer-reviewed journal focusing on evidence-based reports on the value or lack thereof of treatments intended to prevent or delay the onset of maladaptive correlates of aging in human beings. This journal is indexed on PubMed Central, MedLine,

\section{Dovepress}

CAS, Scopus and the Elsevier Bibliographic databases. The manuscript management system is completely online and includes a very quick and fair peer-review system, which is all easy to use. Visit http://www.dovepress. com/testimonials.php to read real quotes from published authors. 